\title{
Customer Relationship Management Scale for the Business-to-Consumer Market: Exploratory and Confirmatory Validation and Models Comparison
}

\author{
Gisela Demo ${ }^{1} \&$ Késia Rozzett ${ }^{2}$ \\ ${ }^{1}$ Anderson School of Management,'University of California, United States \\ ${ }^{2}$ Programa de Pós-Graduação em Administração, Universidade de Brasília, Brazil \\ Correspondence:Gisela Demo, Departamento de Administração da Universidade de Brasília, Campus \\ Universitário Darcy Ribeiro, ICC Norte, Sala B1-576, Asa Norte, Brasilia, DF, Brasil. CEP: 70910-900. Tel: \\ 55-61-31077109. E-mail: giselademo@gmail.com
}

Received: August 9, 2013

Accepted: September 10, 2013

Online Published: October 28, 2013

doi:10.5539/ibr.v6n11p29

URL: http://dx.doi.org/10.5539/ibr.v6n11p29

\begin{abstract}
The main objective of this study was to validate in the United States a previous scale developed and validated in Brazil for the business-to-consumer (B2C) market to assess customers' perceptions regarding aspects they consider relevant in their relationship with companies in general. Brazilian and American Models were also compared. Three studies have been conducted with different national samples for the validation of the Customer Relationship Management Scale in the US. The result was a one-factor model with high reliability and good fit. This research is a starting point to provide a comprehensive valid measure of customer relationship management based on customers' perspectives. As practical implications, the one-factor model could be used as a diagnostic tool to identify aspects in customer relationship management where specific improvements are needed, as well as an instrument of evaluation to help managers better understand how to meet client's needs in order to deliver high-value products and services developing a long-term and profitable relationship.
\end{abstract}

Keywords: customer relationship management (CRM), business-to-consumer market (B2C), scale validation, exploratory factor analysis, confirmatory factor analysis, cross national comparison of models

\section{Introduction}

The main authors of Customer Relationship Management (CRM)(Wilson \& Vlosky, 1997; Campbell, 2003; Zablah et al., 2004; Payne, 2006) agree on the relevance of managing the relationship between organizations and its customers. Thus the adaptation of the organizational capacity to detect opportunities in the market and the constant effort of companies on establishing long term relationships with its business partners, and especially with its customers, has been established as a priority on enterprises (Demo \& Ponte, 2008).

Considering both the strategic relevance of Customer Relationship Management (CRM) for organizations nowadays, and the lack of measuring scales customized for the business-to-consumer (B2C) market as well as the importance of validating a scale in different countries for improved generalizability, the main objective of this study is to validate the Customer Relationship Management Scale (CRMS) in the US, based on the previous CRM scales that Rozzett and Demo (2010a; 2010b; 2011) developed and validated in Brazil. We found some CRM scales in the literature (e.g., Wilson \& Vlosky, 1997; Sin, Tse \& Yim, 2005; Öztaysi, Sezgin \& Özok, 2011) but none focused on the customer's relationship marketing perception in the $\mathrm{B} 2 \mathrm{C}$ market in general.

Furthermore, if the CRMS shows theoretical consistency and also good psychometric indexes when validated in a different country (US), it will be a psychometrically and operationally valid measure to be used in relational studies from both Marketing and Consumer Behavior fields. Additionally, it could be used as a diagnostic tool to identity CRM aspects where specific improvements are needed, as well as an instrument of evaluation to help managers better understand how to meet client's needs, deliver high-value products and services, and develop long-term profitable relationship.

\section{Literature Review}

This section first presents the theoretical background of CRM and after summarizes the studies Rozzett and 
Demo (2010a; 2010b; 2011) conducted to develop and validate the CRM scale, used as basis for this research.

\subsection{Theoretical Background}

It is important to consider the competitiveness perspective on organizational studies. Along with globalization and new technologies, competitiveness is imperative and characterized by the non-stop organizational search for competitive advantage.

Kumar et al. (2011) investigated if market orientation is, indeed, a source of sustainable competitive advantage and discovered a positive effect of market orientation when crossed with business performance on either long or short terms. The study conducted by Mishra (2009) showed that as more organizations realize the significance of becoming customer-centric in today's competitive era, as more they adopted Customer Relationship Management (CRM) as a core business strategy, driving them to the conclusion that CRM can help organizations manage their interactions with customers more effectively in order to maintain competitiveness.

For Grönroos (1994), Sheth and Parvatiyar (2002), CRM or relationship marketing represents a paradigm shift on marketing concepts, a change on marketing orientation from just attracting customers to having customer's retention and loyalty. As stated by Payne (2006), CRM provides opportunities to use information, know clients better, offer value by customized sales and develop long-term relationships. The company should have know-how on processes, operations and integration in order to allow that the core of marketing become the philosophy that guides the business.

McKenna (1991) presents a strategic relationship marketing approach placing the customer in first and changing the marketing role of manipulating customers to making a real commitment with them. The author emphasizes the retention of profitable customers, multiple markets and an approach regarding multifunctional marketing, in which the responsibility for marketing strategies development and relationship with the customer is not limited to the marketing department only.

"Long-term customers buy more, take less of a company's time, are less sensitive to price and bring in new customers. Best of all, they have no acquisition or start-up cost" (Reichheld, 1996). In this sense, competitive advantage can be acquired by knowing the expectations, preferences, and behavior of customers. Thus, retaining customers, developing a relationship and continuously satisfying them can be considered the basis for a successful trajectory for most organizations, according to the author.

Although CRM has become an extremely relevant proposal, the comprehension of what it means is still limited. Many companies make a conceptual mistake by equaling customer relationship marketing to support systems for CRM implementation. Regarding this controversy, Bygstad (2003) conducted a longitudinal 6-year case study of a company implementing CRM both as a marketing principle and as an information system. The author found that from a managerial view CRM projects should be treated as complex challenges, needing tight project control and the application of change management techniques, focusing on the marketing process and data quality. In contrast, it's important to understand that the mechanisms at work at the micro level are only partly controllable by management techniques, so the infrastructure should grow organically.

Payne (2006) stresses that the importance of defining CRM correctly is not a semantic preciousness. Such definition significantly impacts the way CRM is understood, implemented and practiced in organizations. The author highlights that CRM is a strategic holistic approach to manage the relationship with customers in order to create value to the stockholder. Moreover, CRM needs to be infused with strategic vision to create value to the stockholder through the development of relationships with strategic customers, bringing together the potential of information technology (IT) to the relationship marketing strategies that will result in the establishment of profitable long-term relationships.

Zablah et al. (2004) agree that the CRM literature is still inconsistent and highly fragmented due to the lack of a common conceptualization, proposing a delineation of CRM as an "ongoing process that involves the development and leveraging of market intelligence for the purpose of building and maintaining a profit-maximizing portfolio of customer relationships" (p. 475). This idea converges with the conceptual framework presented by Campbell (2003) about the internal processes involved in creating customer knowledge competence composed by four components namely customer information process; marketing-IT (information technology) interface; senior management involvement; and employee evaluation \& reward systems.

Huang and Xiong (2010) notice that CRM has reached a strategic maturity and it influences the entire cycle of life of a product and not only the before or after-sales stages. Still on the enlargement of CRM influence, Ernst, Hoyer, Krafft and Krieger (2011) sustain that its potential has been only investigated on already existent products cases, but it should be considered on the development of new products as well, once their studies showed that 
CRM has a positive correlation with performance and success of new products.

Also considering that corporative culture has not been sufficiently studied on relationship marketing, Iglesias, Sauquet and Montaña (2011) presented a model of corporative culture from a CRM-oriented organization. The results showed two primary factors needed for its effectiveness: "client orientation" and "high level of care for employees". Moreover, other six-shared values (confidence, involvement, teamwork, innovation, flexibility and results orientation) also would facilitate the orientation development towards relationship marketing.

As for literature reviews regarding CRM, Ngai's (2005) first article was considered a milestone regarding the academic literature about customer relationship marketing. It analyzed 205 articles in different databases published in over 85 different academic reviews from 1992 to 2002. Ngai's (2005) study concluded for the force of CRM research, questioning about the low percentage of theoretical reviews related to CRM privacy, and predicting that the field would continue to present significant growth during the next years.

Ngai, Xiu and Chayu (2009) wrote the first academic review on the application of data mining techniques for CRM. The results showed that models of classification and association are the most commonly used in data mining regarding CRM. Besides, customer retention is the most researched area of all and the one-to-one marketing and loyalty programs are the most investigated themes.

Wahlberg et al. (2009) questioned the evolution of CRM research through time and identifying trends and research topics from 4 investigation areas: strategic CRM, analytical CRM, operational CRM and collaborative CRM. The results showed that the number of articles about CRM as a specific topic was relatively low until the end of the nineties, exactly as pointed by Ngai (2005), which confirms the aspect of novelty CRM holds on marketing research. Also, most of researches have been done on strategic CRM, which was the most popular by the end of the studied period of time. Additionally, they have found predominance of research on big companies at the expense of medium and small businesses whose characteristic must be taken into account.

Concerning CRM measures, we found some studies with scale validation that were mostly based in the works of Wilson and Vlosky (1997), Sin, Tse and Yim (2005), Agariya and Singh (2012a), and Rozzett and Demo (2010a; 2010b; 2011).Wilson and Vlosky (1997) developed a CRM scale for the business-to-business (B2B) market and Viana, Cunha Jr and Slongo (2005) adapted it for the industrial sector in Brazil. Sin, Tse and Yim (2005) validated a scale to measure the CRM dimensions practiced by the companies in the financial service sector of Hong Kong. Then, Soch and Sandhu (2008) developed a scale for CRM constructs applied to manufacturing industries in India, Wang and Feng (2008) validated a scale on CRM capability in service industries in China and Öztaysi, Sezgin and Özok (2011) proposed an instrument for the measurement of CRM processes in Turkey. Recently, Agariya\& Singh (2012a; 2012b; 2013) developed a CRM Index for both insurance and banking sectors and a CRM scale for clients of Indian Public Hospitals, and Zulkifli \& Tahir (2012) validated a scale for CRM practices construct consisted of six dimensions of CRM specifically for bank's customers.

Finally, Rozzett and Demo (2010a; 2010b; 2011) conducted three studies in Brazil to develop and validate a scale for the (B2C) market to assess customer's perception of relationship with companies in general. Three customized scales were adapted and validated based on Rozzett and Demo's scale: for amusement parks (Vasconcelos \& Demo, 2012); for video-games (Batelli \& Demo, 2012); and for beverages (Lopes \& Demo, 2012).

\subsection{Development and Validation of the Customer Relationship Management Scale in Brazil}

The studies of the development and validation of the CRMS in Brazil (Rozzett \& Demo, 2010a; 2010b; 2011) were the basis for the validation in the US because it is the only one found on the literature addressed to the B2C market in general. Item generation of the CRMS validated in Brazil was based on a broad literature review regarding CRM (Ryals \& Payne, 2001; Campbell, 2003; Zablah et al., 2004; Ngai, 2005; Payne, 2006; Wahlberg et al., 2009; Kumar et al., 2011), as well as on interviews with various customers from different organizations that highlighted the relevance of items concerning customers satisfaction and also loyalty intention as possibly predictors of a long-term relationship. Regarding the interviews, the analysis of categorical thematic content recommended by Bardin (2011) was used for the identification of categories and its indicators. The categories that emerged from content analysis were consistent with the most recently literature and Rozzett and Demo's (2010a, 2010b) initial pool was composed of 40 items.

As to the theoretical analysis of the items, Rozzett and Demo (2010a, 2010b) followed the steps proposed by Kerlinger and Lee (2008). At first, the items were submitted to semantic analysis and then twelve experts in the CRM field (both professors and practitioners) were exposed to the definition of the construct and to a related explanation. They were asked to assess the fit of the statements to the CRM concept. After the judges' analysis, 
the CRMS counted 26 items with a 5-point Likert scale, varying from "I totally disagree" to "I totally agree".

Thereafter, CRMS was validated through EFA (Rozzett \& Demo, 2010a, 2010b). The results presented a one-factor instrument with 20 items (Rozzett \& Demo, 2010a), namely the complete version, consistent with the literature review. It explained about $40 \%$ of the construct's total variance, had a Cronbach's alpha of .93 and $70 \%$ of the items ranked as excellent, very good and good, according to Comrey and Lee (1992). Nonetheless, Rozzett and Demo (2010b) validated a reduced scale with only 8 items, namely the abridged version, and presented even better indexes: $64 \%$ of total variance explained, a Cronbach's alpha of .92 and better items in terms of validity(excellent and very good items only).

Finally, Rozzett and Demo (2011) validated the CRMS, both complete and abridged versions, through confirmatory factor analysis. The complete version showed high reliability with a Jöreskog's rho greater than .70 ( = .93), as proposed by Chin (1998) and a satisfactory fit, according to Kline $(2011)\left(\chi 2_{(170)}=757.84, \mathrm{p}<\right.$ $0.001 ; \mathrm{NC}=4.46$; $\mathrm{CFI}=.90 ; \mathrm{RMSEA}=.08)$. The abridged version, however presented an unsatisfactory fit $\left(\chi 2_{(20)}=138.43, \mathrm{p}<0.001 ; \mathrm{NC}=6.92 ; \mathrm{CFI}=.96\right.$; RMSEA $\left.=.10\right)$, although it has shown high reliability ( $=.92$ ).

\section{Method}

First we present the review of the scale for application in the US, regarding its translation for English and the content validity of the items. Then, the three studies conducted for the development and validation of the Customer Relationship Management Scale (CRMS) in the United States (US) are detailed. Three different national samples were collected online using MTurk in order to ensure the presence of abroad variety of American customers. This diversification indicates sampling variability and representativeness.

Data from study 1, which had 210 participants, were used to select items based on EFA. Then, CFA was used on data obtained in study 2, which had 425 participants, to examine factor structure, as well as to provide construct validity through convergent validity. Scale reliability was assessed by Cronbach's alpha and Jöreskog's rho. Finally, data from study 3 , which had 415 participants, were used to test the scale generalizability by conducting a replicative analysis on the measurement model used in study 2, and by checking if the structure obtained through the CFA remained stable in a different sample.

For the three samples, data were examined (searched for incorrect values, missing data and outliers) and the assumptions for multivariate analysis were checked, following the procedures recommended by Tabachnick and Fidell (2007) and Hair, Black, Babin, Anderson and Tatham (2009).

\subsection{Review of the Customer Relationship Management Scale for Application in the US}

In order to make the CRMS suitable for application in the US, the 20 items were translated to English by a specialist in translation and retranslated to Portuguese by the authors of the scale. Then, an English Professor from a university in California checked out the translation to English. Following the item generation steps proposed by Kerlinger and Lee (2008), two faculty members from the Marketing area of a Brazilian University and one faculty member and a PhD student from a University in the US served as judges to evaluate the content/validity of the items. As a result, the 20 statements remained for the application in the US, with small adaptations and a 5-point Likert scale, varying from "I totally disagree" to "I totally agree".

\subsection{Study 1: Exploratory Factor Analysis}

The sample for this study was collected online using MTurk. Data were collected from 210 people. Of the employees, $65 \%$ were male, $63 \%$ were White or Caucasian, $55 \%$ were under the age of $26,49.5 \%$ had a Bachelor degree, $43.5 \%$ had been customers of the companies chosen between 1 and 5 years, and $67 \%$ affirmed they purchase from the companies chosen on a weekly (33\%) or monthly (34\%) basis.

The final sample counted with 200 subjects. Hair et al. (2009) say that for an adequate sample size, it is necessary to have between 5 and 10 individuals for each item of the instrument. However, the authors state that any factor analysis with less than 200 individuals can hardly be considered suitable. The sample size with 200 subjects attended, therefore, both criteria.

To perform the EFA, the correlation matrix, the matrix determinant and the results of the Kaiser-Meyer-Olkin (KMO) sampling adequacy test were analyzed regarding factorability. For factor extraction, Principal Components Analysis (PCA) was used. Once the matrix was considered factorable, the eigenvalues, percentage of explained variance of each factor, scree plot graphic and parallel analysis were then examined in order to determine the quantity of factors to be extracted. After defining the quantity of factors, a Principal Axis Factoring (PAF) analysis was run using Promax rotation, since correlation among factors was expected. Cronbach's alpha 
was used to check reliability or internal consistency of each factor.

\subsection{Study 2: Confirmatory Factor Analysis and Construct Validity}

The sample for this study was also collected online using MTurk. Data were collected from 425people. Of the employees, $64 \%$ were male, $55 \%$ were White or Caucasian, $45.5 \%$ were between 26 and 40 years-old, $48 \%$ had a Bachelor degree, $42 \%$ had been customers of the companies chosen between 1 and 5 years, and $49 \%$ affirmed they purchase from the companies chosen on a monthly basis.

The final sample counted with 403 subjects. Byrne (2009) and Kline (2011) state that for a CFA, an adequate sample size would be 20 subjects for variable. On the other hand, Hair et al. (2009) state that a minimum of 200 individuals is always required whereas samples much larger than 400 could make the method very sensitive. So, sample sizes approximately between 200 and 400 are recommended. The sample size with 403 subjects attended, therefore, all the criteria cited.

To determine which structure adjusts better to CRMS, its fit was evaluated by using AMOS through the following indexes: NC (normatized chi-square or chi-square value divided by the model's degrees of freedom $=$ CMIN/DF), CFI (Comparative Fit Index) and RMSEA (Root Mean Square Error of Approximation), as recommended by Kline (2011). The internal consistency was measured through composite reliability, also known as Dillon-Goldstein's rho or Jöreskog's rho, as proposed by Chin (1998). Dillon-Goldstein's rho is a better reliability measure than Cronbach's alpha in Structural Equation Modeling, since it is based on the loadings rather than the correlations between the observed variables.

Finally, construct validity, "the degree to which a measure assesses the construct it is purported to assess" (Peter, 1981: 134), was examined in this study through convergent validity.

\subsection{Study 3: Scale Generalizability}

The sample for this study was collected online using MTurk as well. Data were collected from 305 people. Of the employees, $61 \%$ were male, $70 \%$ were White or Caucasian, $48 \%$ were under the age of $26,50 \%$ had a Bachelor degree, $41.4 \%$ had been customers of the companies chosen between 1 and 5 years, and $41 \%$ affirmed they purchase from the companies chosen on a monthly basis.

The final sample counted with 404 subjects. Byrne (2009) and Kline (2011) state that for a CFA, an adequate sample size would be 20 subjects for variable. On the other hand, Hair et al. (2009) state that a minimum of 200 individuals is always required whereas samples much larger than 400 could make the method very sensitive. The sample size with 403 subjects attended both criteria.

\section{Results}

This section presents the results of exploratory factor analysis, confirmatory factor analysis, construct validity and scale generalizability.

\subsection{Exploratory Factor Analysis}

The analyses' results confirmed the matrix high factorability to perform the exploratory factor analysis. KMO was 0.931 , classified by Kaiser (1974) as marvelous. The determinant of the matrix was extremely close to zero indicating that the number of factors is lower than the number of items. Through Principal Components Analysis, it was possible to decide how many factors would be extracted. The analysis of the criteria adopted (eigenvalues greater than 1.0, explained variance percentage of each factor above 3\%, scree plot graphic visual analysis and parallel analysis) brought us to a one-factor solution, with a possibility of a two factors solution, according to the eigenvalues and explained variance percentage criteria.

When running the Principal Axes Factoring (PAF) analysis for two factors, we found a high-significant correlation between them $(\mathrm{r}=0.744)$, indicating the presence of a second order factor. Therefore, we opted for the one-factor solution. After 4 iterations, the CRMS resulted in a one-factor scale with 14 items, compatible with the theoretical review done, explaining $50 \%$ of the construct's total variance, which can be considered worthy, especially for one-factor structures.

The validity or quality of the items that composed each factor was also analyzed based on Pasquali's (2010) statement that a valid item is the one that well represents the factor, that is, an item with a good factor loading. The minimum acceptable load was .50 (Hair et al., 2009). Comrey and Lee (1992) classified items with loadings higher above or equal .71 as excellent; above or equal .63 as very good; above or equal .55 as good; above or equal .45 as reasonable; and above or equal .32 as poor. Thus, as to the items' quality, $100 \%$ of them were classified as excellent, very good and good. 
Concerning the reliability, internal consistency or precision of the factors, Pasquali(2010) states that values above .70 indicate that the scale is reliable, while values above.80indicate good reliability (Field, 2009). Nunnally and Bernstein (1994) say that "in the early stages of predictive or construct validation research," it may be satisfactory to "have only modest reliability, e.g., .70". For other scenarios, Nunnally and Bernstein (1994) go on to state that .80 or even .90 may be required. Peterson's (1994) meta-analytical study on Cronbach's alpha showed that reliable alphas have a .77 mean and .79 median.

The CRM scale showed high reliability, with alpha coefficient equals to .92 , following the threshold recommended by authors such as Nunnally and Bernstein (1994), and Peterson (1994). Table A1 in Appendix Asummarizes the main information of the scale.

By comparing the CRM scales (both complete and abridged versions) validated in Brazil and the CRMS validated in US, regarding reliability, number of items and validity, it's possible to see similar parameters, as shown on Table 1, driving us to the conclusion that the one-factor structure validated in two different versions in Brazil remained stable when validated in a different country, being suitable for application in US organizations.

Table 1. Comparison among Brazilian and American CRM scales

\begin{tabular}{|c|c|c|c|}
\hline & $\begin{array}{l}\text { CRMS BRAZIL complete } \\
\text { version }(2010)\end{array}$ & $\begin{array}{l}\text { CRMS BRAZIL abridged } \\
\text { version }(2010)\end{array}$ & CRMS US (2012) \\
\hline Reliability & $\alpha=.93$ & $\alpha=.92$ & $\alpha=.92$ \\
\hline Number of items & 20 & 8 & 14 \\
\hline Quality of items & $\begin{array}{l}70 \% \text { classified as excellent, very } \\
\text { good and good }\end{array}$ & $\begin{array}{l}100 \% \text { classified as excellent } \\
\text { and very good }\end{array}$ & $\begin{array}{l}100 \% \text { classified as excellent, very good } \\
\text { and good }\end{array}$ \\
\hline Total variance explained & $40 \%$ & $64 \%$ & $50 \%$ \\
\hline
\end{tabular}

\subsection{Confirmatory Factor Analysis and Construct Validity}

According to Kline (2011), values that indicate satisfactory adjust for a model are: for NC (CMIN/DF), values 2.0 or 3.0 or, at most, up to 5.0; for CFI, values greater than .90 and for RMSEA, values lower than .05 or up to .08 . The one-factor structure model (Figure 1$)$ had 43 parameters and presented a satisfactory fit $\left(\chi 2_{(77)}=\right.$ 256.02, $\mathrm{p}<0.001 ; \mathrm{NC}=3.32 ; \mathrm{CFI}=.95$; RMSEA $=.07)$, confirming the structure obtained through the exploratory factor analysis. The factor loadings of the items in this confirmatory validation were between .58 and .84, which means high-quality items, according to Comrey and Lee (1992).

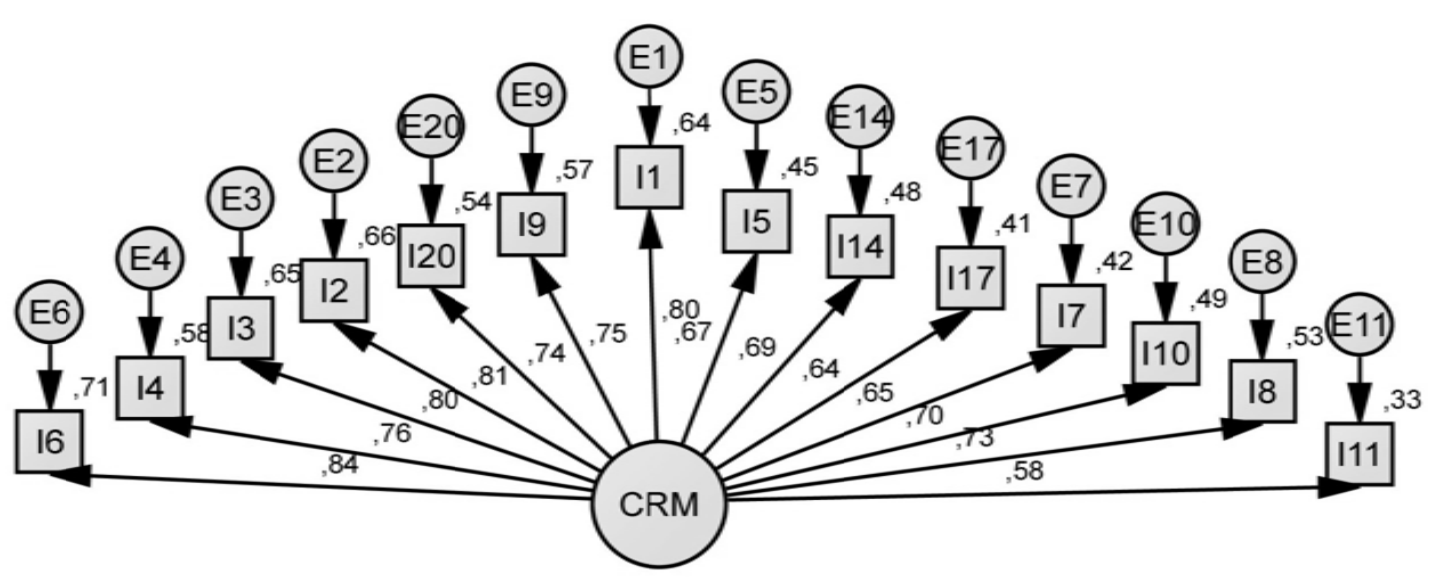

Figure 1. CRM latent variable 
The result of this analysis suggested that Customer Relationship Management for the American customers is a unidimensional construct. It is important to emphasize that, in the confirmatory analysis, the same one-factor structure of 14 items were kept, in agreement with the reviewed literature and with the exploratory validation, such that the interpretation of the items is the same displayed in Table 1. At last, the originated results confirmed the CRMS' validation by showing the conceptual suitability of the structure obtained in the exploratory analysis and satisfactory fit.

By comparing the fits provided in the Brazilian models (complete and abridged versions) to the fit obtained in the American sample, we observe, in general, better fit and indexes in the American model with 14 items. In addition, chi-square difference was significant, indicating that the American model is indeed better than the Brazilian ones. Table 2 shows this comparison.

Table 2. Comparison of Brazilian and American models for CRM

\begin{tabular}{|c|c|c|c|}
\hline & $\begin{array}{l}\text { BRAZILIAN COMPLETE MODEL } \\
(20 \text { items })\end{array}$ & $\begin{array}{l}\text { BRAZILIAN ABRIDGED } \\
\text { MODEL (8 items) }\end{array}$ & $\begin{array}{l}\text { AMERICAN MODEL } \\
\qquad(14 \text { items })\end{array}$ \\
\hline CMIN or $\chi^{2}(p)$ & $757.84(\mathrm{p}<0.001)$ & $138.43(\mathrm{p}<0.001)$ & $256.02(\mathrm{p}<0.001)$ \\
\hline Df & 170 & 20 & 77 \\
\hline $\mathrm{NC}\left(\chi^{2} / \mathrm{df}\right)$ & 4.46 & 6.92 & 3.32 \\
\hline RMSEA & .08 & 0.10 & .07 \\
\hline CFI & .90 & 0.96 & .95 \\
\hline$\Delta \chi^{2}$ & $\Delta \chi_{(93)}^{2}=501.82, \mathrm{p}<0.001$ & $\Delta \chi_{(57)}^{2}=117,59, \mathrm{p}<0.001$ & \\
\hline
\end{tabular}

\subsubsection{Reliability Assessment}

To assess the reliability of the CRM scale, Jöreskog's rho was computed. Chin (1998) recommends that acceptable scores for the Jöreskog's rho should be greater than 0.7 . The result was very satisfactory, presenting a Jöreskog's rho of 94 .

\subsubsection{Construct Validity}

Construct validity is the degree to which a set of measured items actually reflects the theoretical latent construct that those items are supposed to measure (Hair et al., 2009). In this study, the construct validity of the CRMS was examined by assessing convergent validity.

Convergent validity refers to the degree of agreement in two or more measures of the same construct. According to Hair et al. (2009), there are several indicators of convergent validity, for example, examining factor loadings, the reliability of the factors and the variance extracted.

The reliability of the one factor was above .70 ( = .94), indicating appropriate convergence (Hair et al., 2009). In addition, all items of the CRM measure loaded significantly positive on their specified factor (see Figure 1). Moreover, all 14 items had loadings over .5 (Hair et al., 2009), which is indeed a test of convergent validity of the scale. Finally, according to Hair et al. (2009), variances extracted over .5 (or 50\%) are a good rule suggesting appropriate convergence. The extracted variance for the CRMS was .53 (or 53\%), attesting convergent validity. We may thus state that the CRM scale validated in US possessed convergent validity.

\subsection{Scale Generalizability}

Even though our proposed factorial structure has a good fit with the data (Figure 1) and we have used a broad sample from various American costumers, we recognize that the results could be specific to this particular sample. Although it can be said that the sample represents a cross-section of a large number of customers, the generalizability of the CRMS could be still questionable. To provide evidence on generalizability of CRMS, a replicative study on a wide and different sample is essential. Then, we use the measurement model shown on 
Figure 1 with the study 3 sample to test the scale generalizability.

As far as the measurement model is concerned, the data in this study exhibit a satisfactory level of fit with 43 parameters $\left(\chi 2_{(77)}=275.31, \mathrm{p}<0.001 ; \mathrm{NC}=3.57\right.$; $\mathrm{CFI}=.94$; RMSEA $\left.=.08\right)$ and is shown in Figure 2. Moreover, all 14 items were significant and loaded as predicted on their factor. These results provide further evidence to suggest that the proposed scale validated in this study is a reliable operational measure for CRM in the American culture.

To sum up, the results are encouraging in terms of scale generalizability. The 14-item CRM scale proposed in this study was found to have a high degree of reliability and validity and so it can be used to properly understand what aspects American customers consider relevant in their relationship with companies in general and that might influence their shopping experiences, satisfaction and loyalty as well. These results will help both consumer behavior scientists and companies managers better understand how to meet customer's needs in order to deliver high-value products and services and get their loyalty through a long-term and profitable relationship.

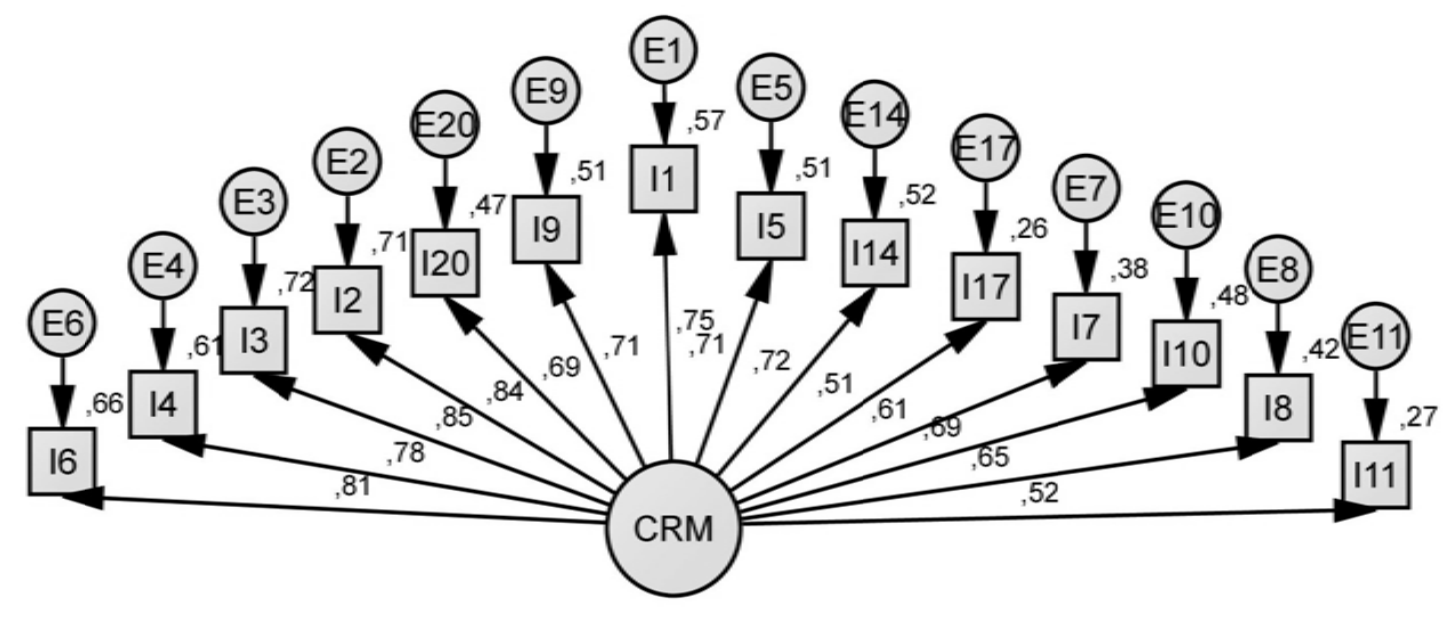

Figure 2. Scale Generalizability

$\chi 2_{(77)}=275.31, \mathrm{p}<0.001 \mathrm{NC}=3.57 ; \mathrm{CFI}=.94 ; \mathrm{RMSEA}=.08$

\section{Discussion}

This section discusses the theoretical consistency of the scale validated in the study, academic and managerial implications of the results obtained and also points out limitations and directions for further research.

\subsection{Theoretical Consistency of the Customer Relationship Management Scale (CRMS)}

This paper reports three studies conducted on the development and validation of a measure of CRM from an American costumers' perspective. The CRMS was found to have a high degree of reliability and construct validity. Although the numbers resulted from the previous analyses performed were very satisfactory, it is also necessary to analyze CRMS's theoretical consistency or validity from the revised literature, verifying if the scale's items are coherent with the theoretical concepts used to support it.

Kerlinger and Lee (2008) have said that it is not appropriate to hold an item that has only mathematic meaning, for the factor must be relevant in the scientific theoretical context. Furthermore, validity of expression must be established before any theory test when using CFA, because without an understanding of the content or meaning of each item, it is impossible to express and correctly specify a theory of measurement (Hair et al., 2009).

All items of the CRMS have theoretical support indeed, and are relevant to the customer relationship assessment. The item with the highest factor loading, regarding respectful treatment to the client, is sustained by Demo et al. (2011) who also argue that buying experiences must go beyond the mere satisfaction of customer needs. In fact, in order to exceed customer's expectations, a company must provide experiences that positively surprise them on a recurring basis so that a long-term relationship can be established. The authors also highlight that companies should be concerned about making their customers feel important and unique and the offer of a personalized 
service is, in this matter, a relevant indicator. Furthermore, customers' identification with the company can be a useful indicative of their appreciation and loyalty to it (Demo \& Ponte, 2008).

The item regarding repurchase intention was ratified as an indicator of relationship, confirming what Ravald and Grönroos (1996) and Reichheld and Sasser (1990) affirmed about repurchase intention as a loyalty index. The item related to trust endorse the ideas of authors as Brei and Rossi (2005), Sirdeshmukh, Singh and Sabol (2002), and Morgan and Hunt (1994) who discuss trust as a key point in relational exchanges and as having an important role in reducing the asymmetry in the company-customer relationship to make it long lasting. Additionally, Demo et al. (2011) argue that a company only earns customers' confidence when their problems and demands are efficiently solved.

The item concerning recommendation of a company to friends and family, in turn, reinforces Payne's (2006) statement that loyal customers not only buy repeatedly, but also go a step further recommending the company to new customers. These recommendations reduce future customers' acquisition costs (Ravald \& Grönroos, 1996).

Moreover, Payne (2006) attests that relationships are developed to the extent that the parties know each other. Hence the importance of companies' efforts to get to know their customers preferences, questions and suggestions. Additionally, authors such as Sheth and Parvatiyar (2002), and Payne (2006) point out that loyalty should be rewarded - which is translated into one of the items of the scale.

Finally, items that address important aspects of the business-to-consumer relationship, as product quality, cost-effective and facilities (either physical or virtual) must be constantly evaluated as suggested by Grönroos (1994) and McKenna (1991).

Table 3 summarizes the 14 items of the CRMS and their theoretical background.

Table 3. Items of the customer relationship management scale and their theoretical background

\begin{tabular}{|c|c|}
\hline Item & Theoretical Background \\
\hline I6. This companytreats its customers with respect. & Demo and Ponte (2008) \\
\hline I4. My shopping experienceswith thiscompanyare better than I expected. & Demo, Rozzett, Ponte, Ferreira and Mendes (2011) \\
\hline I3. Thiscompanytreatsmeas an important customer. & Demo and Ponte (2008) \\
\hline I2. Irecommend thiscompanytofriendsandfamily. & Ravald and Grönroos (1996), Payne (2006) \\
\hline I1. Thiscompanydeservesmytrust. & $\begin{array}{l}\text { Brei and Rossi (2005), Sirdeshmukh, Singh and Sabol (2002), } \\
\text { Morgan and Hunt (1994) }\end{array}$ \\
\hline I9. This company solves problems efficiently. & Demo, Rozzett, Ponte, Ferreira and Mendes (2011) \\
\hline I20. The products/services sold by this company are high quality. & Grönroos (1994), McKenna (1991) \\
\hline I5. I identify myselfwiththis company. & Demo and Ponte (2008) \\
\hline I4. I'm willing to buy other products/services from this company. & Ravald and Grönroos (1996), Reichheld and Sasser (1990) \\
\hline I7. This company offers personalized customer service. & Demo and Ponte (2008) \\
\hline $\begin{array}{l}\text { I10. This company tries to get to know my preferences, questions and } \\
\text { suggestions. }\end{array}$ & Payne (2006) \\
\hline $\begin{array}{l}\text { I17. This company has good facilities (either physical, in case of stores, } \\
\text { or virtual, in case of websites). }\end{array}$ & Grönroos (1994), McKenna (1991) \\
\hline $\begin{array}{l}\text { I8. The products/services sold by this company are a good value (the } \\
\text { benefits exceed the cost). }\end{array}$ & Grönroos (1994), McKenna (1991) \\
\hline I11. This company rewards my loyalty. & Sheth and Parvatiyar (2002), Payne (2006) \\
\hline
\end{tabular}

Thereafter, we might affirm that CRMS's 14 items indeed have theoretical support, greatly corresponding to the literature reviewed throughout this paper.

The items of the Customer Relationship Management Scale developed and validated in Brazil by Rozzett and Demo (2010a; 2010b; 2011) were the basis for the validation conducted in the US. The comparison between the 
scales, regarding the exploratory and the confirmatory factor analyses, drove us to the conclusion that the one-factor structure validated in Brazil remained stable in the American sample with respect to its validity and reliability, but the model validated in the US presented a leaner structure compared to the Brazilian complete version.

We should emphasize that respondents' questionnaire fatigue contributes to the response rate (Saunders, Lewis \& Thornhill, 2009) and therefore shorter questionnaires may have a greater response rate. The problem with the Brazilian abridged version ( 8 items) is that its few numbers of items could probably compromise the comprehensiveness of the construct. Pasquali (2010) argues that a construct with about 15 or 20 items with good factor loadings is reliably stable and well represented. Besides, the 14-item-measurement model used to run the CFA, through the structure equation modeling, also showed better fit than both the 20 -item-model and the 8-item-model, indicating that the American version of CRMS could be more suitable for test in other countries and cultures.

In sum, the three studies performed in this paper produce a one-factor measure for CRM with reliability, construct validity and theoretical consistency that may be used in the US to assess the relationship between customers and companies.

\subsection{Academic and Managerial Implications}

The present study makes both academic and practical contributions, and we suggest several applications for the research.

First, it is an attempt to develop a lean model of CRM specifically designed for the B2C market. Second, by exploring the strategic nature of CRM we attempted to provide a clearer conceptualization of the construct. Third, we found empirical evidence that the CRM scale validated in the US is both reliable and valid constituting a measure that can be used in relational studies from both Marketing and Consumer Behavior fields. This leads us to a new purpose of how CRM aspects can be managed in order to provide superior organizational outcomes.

As to the managerial implications, our scale might be used as an instrument of evaluation to help managers better understand how to meet client's needs in order to deliver high-value products and services and get their loyalty through a long-term and profitable relationship. Beyond, there is theoretical and empirical evidence that CRM is a critical success factor for business performance (e.g., Ryals \& Knox, 2001; Ryals \& Payne, 2001; Sheth \& Sisodia, 2001; Sheth \& Sisodia, 2002; Sin, Tse \& Yim, 2005; Huang \& Xiong, 2010, Ernst et al., 2011). Consequently, the CRMS may support managers decision-making and problem-solving regarding identification of CRM areas where specific improvements are needed in order to achieve better organizational outcomes.

\subsection{Limitations and Directions for Future Research}

Our proposal represents a first attempt to develop and test a CRM scale designed specifically for the B2C market. The first limitation is that the present findings are therefore indicative rather than conclusive. In spite of the scale's validation in Brazil, it would be useful to further assess its generalizability to other business environments such as European and Asian countries.

Another limitation is the cross-sectional nature of the data. Even by running the CRM structure obtained through factor analysis in a different sample in order to attest the scale's generalizability, the development of a time-series database and testing of the CRM structure validated here in a longitudinal framework would provide a refinement of the scale and also an improvement of some of its indexes obtained through confirmatory factor analysis (e.g., NC and RMSEA). Continued validations of the CRMS is recommended based on further research about new CRM trends, perspectives and also contemplating changes in business environments.

In this meaning, there could be a need of alteration or even deletion of original items. Additionally, items representing aspects of CRM very disclosed and mentioned as important in literature could be included in further validations, such as: the existence of communication channels for customers' complaints and suggestions (e.g., toll free, online customer service, etc), the encouragement of interaction among its customers (e.g., events, Facebook, etc), the offering of convenience to the customers (e.g., online services, home delivery, 24-7 customer service), the importance of the company be socially and environmentally friendly, if there are competitors to the company that have the same importance to its clients, the disclosure of information about the companies' policies, projects, products/services and new releases, and so forth.

\section{Conclusion}

We may conclude, in spite of the limitations pointed, that the main objective of this study was reached and an instrument to assess what aspects American customers rank as relevant regarding CRM was produced showing 
theoretical consistency, reliability, construct validity. Considering the increasing research attention to the new strategic role of CRM in organizations, this study provides an operational measure of it. The findings found here are not intended to be conclusive or limiting but offer a useful starting point from which further theoretical and empirical research of customer relationship management in the $\mathrm{B} 2 \mathrm{C}$ market can be built.

\section{Acknowledgement}

We would like to thank the Brazilian National Counsel of Technological and Scientific Development (CNPq) for the grant that funded this research.

\section{References}

Agariya, A. K., \& Singh, D. (2012a). CRM Scale development \& validation in Indian insurance sector. Journal of Internet Banking and Commerce, 17(2), 1-21.

Agariya, A. K., \& Singh, D. (2012b). CRM Index development and validation in Indian banking sector. International Journal of Customer Relationship Marketing and Management, 3(2), 10-32. http://dx.doi.org/10.4018/jcrmm.2012040102

Agariya, A. K., \& Singh, D. (2013). CRM scale development and validation scale in Indian public hospitals. Journal of Health Management, 15(2), 275-291. http://dx.doi.org/10.1177/0972063413489035

Bardin, L. (2011). Análise de conteúdo. Lisboa: Edições 70.

Batelli, L. S., \& Demo, G. (2012, October). Desenvolvimento e validação de uma escala para avaliar o relacionamento entre os jogadores e os jogos do Nintendo Wii. Anais do Encontro Nacional de Engenharia de Produção, Bento Gonçalves, RS, Brazil.

Brei, V. A., \& Rossi, C. A. (2005). Confiança, valor percebido e lealdade em trocas relacionais de serviço: um estudo com usuários de internet banking no Brasil. Revista de Administração Contemporânea, 9(2), 152-163. http://dx.doi.org/10.1590/S1415-65552005000200008

Bygstad, B. (2003). The implementation puzzle of CRM systems in knowledge-based organizations. Information Resources Management Journal, 16(4), 33-45. http://dx.doi.org/10.4018/irmj.2003100103

Byrne, B. M. (2009). Structural equation modeling with AMOS: basic concepts, applications, and programming (2nd ed.). New York: Routledge.

Campbell, A. J. (2003). Creating customer knowledgement competence: managing customer relationship management programs strategically. Industrial Marketing Management, 32, 375-383. http://dx.doi.org/10.1016/S0019-8501(03)00011-7

Chin, W. W. (1998). The partial least squares approach for structural equation modeling. In G. A. Marcoulides (Ed.), Modern methods for business research (pp. 295-236). London: Lawrence Erlbaum Associates.

Comrey, A. L., \& Lee, H. B. (1992). A first course in factor analysis (2nd ed.). Hillsdale, NJ: Lawrence Erlbaum Associates.

Demo, G., \& Ponte, V. (2008). Marketing de relacionamento (CRM): Estado da arte e estudos de casos. Brasília, Brazil: Atlas.

Demo, G., Rozzett, K., Ponte, V., Ferreira, L. A., \& Mendes, N. M. D. (2011). Marketing de Relacionamento (CRM): Estado da arte, produção nacional na primeira década do milênio e agenda de pesquisa. Encontro da Associação Nacional de Pós-Graduação e Pesquisa em Administração, Rio de Janeiro, RJ, Brazil, 30.

Ernst, H., Hoyer, W., Krafft, M., \& Krieger, K. (2011). Customer relationship management and company performance: the mediating role of new product performance. Journal of the Academy of Marketing Science, 39(2), 290-306. http://dx.doi.org/10.1007/s11747-010-0194-5

Field, A. (2009). Discovering statistics using SPSS (3rd ed.). Thousand Oaks, CA: Sage.

Grönroos, C. (1994). From marketing mix to relationship marketing. Management Decision, 32(2), 4-20. http://dx.doi.org/10.1108/00251749410054774

Hair, J. F., Black, W. C., Babi, B. J., Anderson, R. E., \& Tatham, R. L. (2009). Análise multivariada de dados (6th ed.). Porto Alegre: Bookman.

Huang, J., \& Xiong, W. (2010). The effect of win-back investment on lost consumers' intention of reinitiating relationship. Frontiers of Business Research in China, 4(3), 485-497. http://dx.doi.org/10.1007/s11782-010-0107-y 
Iglesias, O., Sauquet, A., \& Montaña, J. (2011). The role of corporate culture in relationship marketing. European Journal of Marketing, 45(4), 631-650. http://dx.doi.org/10.1108/03090561111111361

Kaiser, H. F. (1974). An index of factorial simplicity. Psychometrika, 39(1), 31-36. http://dx.doi.org/10.1007/BF02291575

Kerlinger, F. N., \& Lee, H. B. (2008). Foundations of behavioral research (5th ed.). Independence, KY: Wadsworth Thomson.

Kline, R. B. (2011). Principles and practice of structural equation modeling (3rd ed.). New York: The Guilford Press.

Kumar. V., Jones, E., Venkatesan, R., \& Leone, R. P. (2011). Is market orientation a source of sustainable competitive advantage or simply the cost of competing? Journal of Marketing, 75(1), 16-30. http://dx.doi.org/10.1509/jmkg.75.1.16

Lopes, C., \& Demo, G. (2012). Desenvolvimento e validação das escalas de relacionamento com clientes da cerveja Skol e do guaraná Antarctica. Anais do Encontro de Marketing da ANPAD, Curitiba, PR, Brazil.

McKenna, R. (1991). Relationship marketing. Menlo Park, CA: Addison-Wesley.

Menard, S. (2002). Applied logistic regression analysis. Thousand Oaks, CA: Sage.

Mishra, A., \& Mishra, D. (2009). Customer Relationship Management: implementation process perspective. Acta Polytechnica Hungarica, 6(4), 83-99.

Morgan, R. M., \& Hunt, S. D. (1994). The commitment-trust theory of relationship marketing. Journal of Marketing, 58, 20-38. http://dx.doi.org/10.2307/1252308

Myers, R. (1990). Classical and modern regression with applications (2nd ed.). Boston: Duxbury.

Ngai, E. W. T. (2005). Customer relationship management research (1992-2002): an academic literature review and classification. Marketing Intelligence \& Planning, 23(6-7), 582-605. http://dx.doi.org/10.1108/02634500510624147

Ngai, E. W. T., Xiu, L., \& Chau, D. C. K. (2009). Application of data mining techniques in customer relationship management: A literature review and classification. Expert Systems with Applications, 36, 2592-2602. http://dx.doi.org/10.1016/j.eswa.2008.02.021

Nunnally, J. C., \& Bernstein, I. H. (1994). Psychometric theory (3rd ed.). New York: McGraw-Hill.

Öztaysi, B., Sezgin, S., \& Özok, A. F. (2011). A measurement tool for customer relationship management processes. Industrial Management \& Data Systems, 111(6), 943-960. http://dx.doi.org/10.1108/02635571111144982

Pasquali, L. (2010). Instrumentação psicológica: fundamentos e práticas. Porto Alegre: Artmed.

Payne, A. (2006). Handbook of CRM: Achieving excellence in customer management. Oxford: Elsevier.

Peter, J. P. (1981). Construct validity: a review of basic issues and marketing practices. Journal of Marketing Research, 18, 133-1451. http://dx.doi.org/10.2307/3150948

Peterson, R. A. (1994). A meta-analysis of Cronbach's coefficient alpha. Journal of Consumer Research, 21, 381-391. http://dx.doi.org/10.1086/209405

Ravald, A., \& Grönroos, C. (1996). The value concept and relationship marketing. European Journal of Marketing, 30(2), 19-30. http://dx.doi.org/10.1108/03090569610106626

Reichheld, F. F. (1996). Learning from customer defections. Harvard Business School Press, 74, 56-69.

Reichheld, F. F., \& Sasser, W. E. Jr. (1990). Zero defections-quality comes to services. Harvard Business Review, 107-111.

Rozzett, K., \& Demo, G. (2010a, October). Desenvolvimento e validação da Escala de Relacionamento com Clientes (ERC). Encontro Nacional de Engenharia de Produção, São Carlos, SP, Brazil.

Rozzett, K., \& Demo, G. (2010b). Desenvolvimento e validação da Escala de Relacionamento com Clientes $\begin{array}{lllll}\text { (ERC). Revista } & \text { Administração } & \text { 383-395. }\end{array}$ http://dx.doi.org/10.1590/S0034-75902010000400004

Rozzett, K., \& Demo, G. (2011). Escala de Relacionamento com Clientes (ERC): validação fatorial confirmatória por meio da modelagem por equações estruturais. In Congresso Iberoamericano de 
Psicologia das Organizações e do Trabalho, 2. Florianópolis: SBPOT.

Ryals, L., \& Knox, S. (2001). Cross-functional issues in the implementation of relationship marketing through customer relationship management. European Management Journal, 19(5), 534-542. http://dx.doi.org/10.1016/S0263-2373(01)00067-6

Ryals, L., \& Payne, A. (2001). Customer relationship management in financial services: towards information-enabled relationship marketing. Journal of Strategic Marketing, 9(1), 3-27. http://dx.doi.org/10.1080/713775725

Saunders, M., Lewis, P., \& Thornhill, A. (2009). Research methods for business students (5th ed.). London: FT/Prentice Hall.

Sheth, J. N., \& Parvatiyar, A. (2002). Evolving relationship marketing into a discipline. Journal of Relationship Marketing, 1(1), 3-16. http://dx.doi.org/10.1300/J366v01n01_02

Sheth, J. N., \& Sisodia, R. S. (2001). High performance marketing: marketing must become a leader for change across the corporation. Marketing Management, 10(3), 18-23.

Sheth, J. N., \& Sisodia, R. S. (2002). Marketing productivity: issues and analysis. Journal of Business Research, 55(5), 349-362. http://dx.doi.org/10.1016/S0148-2963(00)00164-8

Sin, L. Y. M., Tse, A. C. B., \& Yim, F. H. K. (2005). CRM: conceptualization and scale development. European Journal of Marketing, 39(11/12), 1264-1290. http://dx.doi.org/10.1108/03090560510623253

Sirdeshmukh, D., Singh, J., \& Sabol, B. (2002). Consumer trust, value, and loyalty in relational exchanges. Journal of Marketing, 66(1), 15-37. http://dx.doi.org/10.1509/jmkg.66.1.15.18449

Soch, H., \& Sandhu, H. S. (2008). Does Customer Relationship Management affect firm performance? Global Business Review, 9(2), 189-206. http://dx.doi.org/10.1177/097215090800900202

Tabachnick, B., \& Fidell, L. S. (2007). Using multivariate statistics (5th ed.). San Francisco: Allyn and Bacon.

Vasconcelos, H., \& Demo, G. (2012). Enchant to retain: an instrumental study about the relationship between Walt Disney World Parks and its Brazilian customers. Anais do International Conference on Industrial Engineering and Operations Management, Guimarães, Portugal, 18.

Viana, D. A., Cunha Jr, M. V. M., \& Slongo, L. A. (2005). Medindo o conceito de marketing de relacionamento no contextobrasileiro: a validação de umaescala no setor industrial. Anais do Encontro da ANPAD, Brasília, DF, Brazil, 29.

Wahlberg, O., Strandberg, C., Sundberg, H., \& Sandberg, K. W. (2009). Trends, topics and under researched areas in CRM Research. International Journal of Public Information Systems, 3(1), 191-208.

Wang, Y., \& Feng, H. (2008). CRM capability in service industries: conceptualization and scale development. Proceedings of 2008 IEEE International Conference on Service Operations and Logistics, and Informatics, Beijing, China. http://dx.doi.org/10.1109/SOLI.2008.4686367

Wilson, E. J., \& Vlosky, R. P. (1997). Partnering relationship activities: building theory from case study research. Journal of Business Research, 39(1), 59-70. http://dx.doi.org/10.1016/S0148-2963(96)00149-X

Zablah, A. R., Bellenger, D. N., \& Johnston, W. J. (2004). An evaluation of divergent perspectives on customer relationship management: towards a common understanding of an emerging phenomenon. Industrial Marketing Management, 33, 475-489. http://dx.doi.org/ 10.1016/j.indmarman.2004.01.006

Zulkifli, Z., \& Tahir, I. M. (2012). Developing and validating Customer Relationship Management (CRM) practices construct. International Journal of Business and Behavioral Sciences, 2(1), 35-48. 


\section{Appendix A: Characterization of items}

Table A1. Description of the customer relationship management scale items

\begin{tabular}{|c|c|c|c|c|}
\hline Item & Description & Quality & Loading & Communalities \\
\hline I6 & This company treats its customers with respect. & Excellent & .85 & .74 \\
\hline I4 & My shopping experiences with this company are better than I expected. & Excellent & .79 & .65 \\
\hline $\mathrm{I} 3$ & This company treats me as an important customer. & Excellent & .79 & .68 \\
\hline I 2 & I recommend this company to friends and family. & Excellent & .77 & .69 \\
\hline I1 & This company deserves my trust. & Very good & .69 & .56 \\
\hline I9 & This company solves problems efficiently & Very good & .69 & .51 \\
\hline $\mathrm{I} 20$ & The products/services sold by this company are high quality. & Very good & .66 & .58 \\
\hline I5 & I identify myself with this company. & Very good & .66 & .55 \\
\hline I14 & I'm willing to buy other products/services from this company. & Very good & .64 & .61 \\
\hline I7 & This company offers personalized customer service. & Good & .61 & .50 \\
\hline $\mathrm{I} 10$ & This company tries to get to know my preferences, questions and suggestions. & Good & .61 & .52 \\
\hline I17 & $\begin{array}{l}\text { This company has good facilities (either physical, in case of stores, or virtual, in } \\
\text { case of websites). }\end{array}$ & Good & .61 & .48 \\
\hline I8 & $\begin{array}{l}\text { The products/services sold by this company are a good value (the benefits exceed } \\
\text { the cost) }\end{array}$ & Good & .60 & .52 \\
\hline I11 & This company rewards my loyalty. & Good & .55 & .49 \\
\hline
\end{tabular}

Note: total variance explained $=50 \%$; total of items $=14$ items.

\section{Copyrights}

Copyright for this article is retained by the author(s), with first publication rights granted to the journal.

This is an open-access article distributed under the terms and conditions of the Creative Commons Attribution license (http://creativecommons.org/licenses/by/3.0/). 